\title{
Asymmetric Interaction between Aphis spiraecola and Toxoptera citricida on Sweet Orange Induced by Pre-Infestation
}

\author{
Jing Gao ${ }^{1}$, Steve Arthurs ${ }^{2}$ and Runqian Mao ${ }^{1, *}$ \\ 1 Guangdong Key Laboratory of Animal Conservation and Resource Utilization, Guangdong Public \\ Laboratory of Wild Animal Conservation and Utilization, Guangdong Institute of Applied Biological \\ Resources, Guangdong Academy of Science, Guangzhou 510260, China; gaoj@giabr.gd.cn \\ 2 Biobee USA, Altamonte Springs, FL 32714, USA; stevenarthurs55@gmail.com \\ * Correspondence: maorun@giabr.gd.cn
}

Received: 15 May 2020; Accepted: 1 July 2020; Published: 3 July 2020

\begin{abstract}
Indirect interactions between herbivorous insects that share the same host have been focused on insects feeding on herbaceous plants, while few studies investigate similar interactions on woody plants. We investigated performance and feeding behavior of two citrus aphids, Aphis spiraecola Patch and Toxoptera citricida Kirkaldy, on sweet orange as affected by prior infestation of conspecifics and heterospecifics. Results showed that pre-infestation-induced interactions between A. spiraecola and $T$. citricida were asymmetric, with $A$. spiraecola gaining more fitness. In detail, pre-infestation by A. spiraecola decreased adult weight, enhanced survival rate and accelerated phloem sap acceptance of conspecifics. However, A. spiraecola pre-infestation did not affect performance or feeding behavior of T. citricida. In another infestation sequence, the pre-infestation of $T$. citricida did not affect conspecifics, but positively affected heterospecifics, indicated as a decreased pre-reproductive period, enhanced survival rate, adult weight, fecundity, and feeding efficiency, i.e., faster access and acceptance of phloem sap, and longer phloem sap ingestion duration. Furthermore, we found A. spiraecola pre-infestation enhanced amino acid concentration, amino acid to sugar ratio, activated salicylic acid and jasmonic acid marker gene expression, while T. citricida pre-infestation only depressed jasmonic acid marker gene expression. Changes in nutrient and phytohormone-dependent defense probably underlie the asymmetric effect.
\end{abstract}

Keywords: aphid performance; feeding behavior; phytohormone-dependent defense; plant nutrition

\section{Introduction}

Infestation by herbivorous insects can indirectly affect the performance of subsequent herbivores positively, negatively, or neutrally, depending on the insect species, duration, and intensity of infestation [1,2]. In response to insect attack, plants show morphological and physiological changes [3]. These changes in plant quality may affect host selection, survival, fecundity, and population dynamics of any subsequent infested herbivores $[4,5]$. Therefore, these plant-mediated interactions may influence the population dynamics and community structure of herbivorous insects [6].

The performance of herbivorous insects can be affected by pre-infestation of both conspecific and heterospecific species. Many studies have measured plant-mediated inter-specific interactions between two herbivore species by transferring one insect species onto plants, and then measuring the survival, growth or insect number of the subsequently infested heterospecifics $[7,8]$. Similarly, the intra-specific interaction was detected by transferring insects onto plants and then measuring performance of subsequently infested conspecifics. The plant-mediated intra-specific effect may oppose or synergize that of the inter-specific effect. For example, conspecific pre-infestation increased the number of 
nymphs produced by Myzus persicae [9], while Bemisia tabaci pre-infestation reduced M. persicae fecundity [1]. Nevertheless, few studies have simultaneously investigated both intra- and inter-specific effects mediated by the same host plant [10]. Furthermore, while plant-mediated interactions between herbivorous insects have been widely reported for herbaceous plants, similar studies on woody plants have been largely overlooked. Moreover, in the latter case, most studies have focused on galling insects [11,12].

During the process of infestation, herbivorous insects induce multiple plant defense responses [13]. Phytohormone-dependent signaling, such as salicylic acid (SA) and jasmonic acid (JA), is important for plants to resist herbivore feeding [14]. While chewing insects mainly induce a JA-dependent defense, most sap-sucking insects such as aphids typically induce an SA-dependent defense [15]. These phytohormone-dependent defenses could affect the development and fecundity of subsequent infested insects. For example, the pre-infestation of B. tabaci induced an accumulation of SA, which prolonged developmental time and reduced fecundity of conspecifics [16]. An Acyrthosiphon pisum pre-infestation repressed JA synthesis, which decreased pre-reproductive period and increased fecundity of conspecifics [17]. In addition to plant-induced defense, nutrient change induced by herbivores may also influence the performance of subsequent infested herbivores. As nitrogen is often a limiting factor for herbivorous insects, the content of nitrogenous nutrition is often positively correlated with insect performance $[18,19]$. For example, M. persicae performed better on brassica plants that were already infested by conspecifics, due to a more favorable amino acid to sugar ratio [9].

Citrus is a globally important fruit tree, with exposure to a wide variety of insect pests [20]. Aphids are common pests that feed on citrus flush shoots and young leaves, impacting yields through decreased shoot growth, virus transmission, and facilitating fungus development by secreting honeydew [21,22]. Among them, Toxoptera citricida Kirkaldy and Aphis spiraecola Patch are common species and cause major damage [23]. Toxoptera citricida is oligophagous, feeding within the Rutaceae and is an efficient vector of Citrus tristeza virus [24]. By contrast $A$. spiraecola is more polyphagous, feeding on Pyrus, Prunus, Malus, and Citrus spp. [25]. Aphis spiraecola can transmit Citrus yellow vein clearing virus and Citrus tristeza virus [26,27].

In spite of the co-occurrence, the influence of plant-mediated intra- and inter-specific interactions between $A$. spiraecola and T. citricida has not been reported. In this paper, we quantified (1) life history parameters, including survival rate, adult weight, pre-reproductive period and fecundity of aphid feeding on plants pre-infested by conspecific and heterospecific individuals, (2) the feeding behavior of aphids tested by electrical penetration graph (EPG) technique as affected by conspecific and heterospecific pre-infestation, (3) total amino acid and soluble sucrose concentration and SA/JA marker genes expression in pre-infested citrus plants.

\section{Materials and Methods}

\subsection{Experimental Plants and Aphid Culture}

The sweet orange Citrus sinensis (L.) Osbeck were about 18 months old and were grown in 8 L pots. Plants were watered twice a week and fertilized with a 20-10-20 fertilizer solution (Haidesi fertilizer company, Weifang, Shandong, China) weekly. Plants were maintained in a growth chamber under 16:8 h photoperiod (day:night), $25{ }^{\circ} \mathrm{C}$ temperature, and $60-80 \%$ relative humidity. Two weeks before the experiment, plants were pruned to promote flushing.

Both A. spiraecola and T. citricida were obtained in 2018 from citrus orchards at Guangzhou, China. Wingless parthenogenetic females of two aphid species were separately maintained on different sweet orange plants in the growth chamber. Plants were covered with nylon mesh bags to prevent aphid dispersion. 


\subsection{Aphid Pre-Infestation Procedure}

When shoots were approximately $2 \mathrm{~cm}$ long, $10 \mathrm{~A}$. spiraecola or T. citricida fourth instar nymphs were transferred to a single new shoot and restricted by nylon mesh bags. After $48 \mathrm{~h}$, the aphids were removed using a soft paint bush. Control shoots without aphids were similarly caged with nylon mesh bags for $48 \mathrm{~h}$. Thus, there are three treatments (A. spiraecola pre-infestation, T. citricida pre-infestation, and control) in this study. The treated shoots were then infested with A. spiraecola or T. citricida to investigate plant-mediated indirect intra- and inter-specific effects. The number of treatments, aphid performance bioassay, and aphid feeding behavior analysis were described in the following sections.

Additional pre-infested and control shoots (five shoots per treatment) were excised, frozen in liquid nitrogen and stored at $-80^{\circ} \mathrm{C}$ for later analysis of amino acid concentration, sugar concentration, and gene expression.

\subsection{Aphid Performance Bioassay}

Several life history parameters, including survival rate, pre-reproductive period, fecundity, and adult weight were evaluated to determine the effects of pre-infestation on performance of subsequent aphids on the pre-infested and control shoots. To determine survival, seven newly emerged nymphs were introduced to each shoot and survival was recorded daily until the last nymph molting (six days). Survival rate (\%) was calculated as the number of survived aphids divided by the number of total introduced aphids. After survival determination, the number of aphids on each shoot was adjusted to two to assess fecundity. Aphids were checked every $12 \mathrm{~h}$ to record the pre-reproductive period (days), and then every $24 \mathrm{~h}$ to record cumulative number of nymphs produced until adult aphids were 14 days old (early fecundity). Nymphs were removed daily to prevent populations increasing and facilitate counting. For the adult weight determination, six newly emerged nymphs were transferred to each pre-treated shoot. After 8 days, when aphids entered adult stage, their weights $(\mathrm{mg})$ were measured individually with a microbalance (precision $0.1 \mathrm{mg}$ ). Aphid responses were measured from 15 shoots per treatment for each aphid species, and average data from one shoot was considered as a replicate.

\subsection{Aphid Feeding Behavior}

The electrical penetration graph (EPG) method can record the activity and locations of aphid stylets [28]. The feeding behaviors of $A$. spiraecola and T. citricida were studied according to the methods we previously used [29]. Apterous adults were starved for $8 \mathrm{~h}$ before experiments. Subsequently, a gold wire was attached to the dorsal side using conductive silver glue and connected to a copper extension wire inserted to an electro penetration graph (EPG) headstage amplifier. Another copper electrode was inserted into the soil. Individual aphids were placed on a shoot, and plants were placed in Faraday cages and subject to EPG monitoring over an $8 \mathrm{~h}$ period. The waveforms produced from EPG system included non-penetration (Np); pooled pathway phase activities (C), intracellular puncture $(\mathrm{Pd})$, salivary secretion into sieve elements (E1), passive phloem ingestion (E2), and xylem absorption (G). Both con- and heterospecific pre-infestation treatments and control plants were included in the study, with 19-23 replicates per treatment.

The recorded EPGs were analyzed according to the waveform type and duration. A total of 12 parameters were analyzed. Six parameters are the total duration of the six described waveforms, another six parameters related to resistant against aphids are as follows [30]: (1) One parameter related to surface resistance is the time from onset of EPG recording to first probe (Pd); (2) Two parameters related to epidermis/mesophyll resistance and mesophyll/phloem resistance are the number of probes before first E1 and the minimum duration of C before first E1, respectively; (3) Two parameters reflecting the ease that aphids establish phloem access and acceptance are the time to first E1, and time to first sustained E2 from onset of EPG recording, respectively; (4) One parameter reflecting plant suitability is the average period of $\mathrm{E} 2$ (i.e., total time in E2 divided by the number of $\mathrm{E} 2$ waveforms per aphid). 


\subsection{Total Amino Acid and Soluble Sugar Concentration}

Citrus leaves collected from five shoots per treatment (from 2.2) were assessed for total amino acid concentration. Leaves were used based on their similar relative amino acid concentration to that assessed from the phloem sap [31,32]. For each sample, $0.08 \mathrm{~g}$ leaf tissue was homogenized in a $0.72-\mathrm{mL}$ phosphate buffer saline $(0.01 \mathrm{~mol} / \mathrm{L}, \mathrm{pH}=7)$ and centrifuged at $3500 \mathrm{rpm}$ for $10 \mathrm{~min}$. The supernatants were assessed using standard amino acid assay procedures of the total amino acid assay kit (Nanjing Jiancheng Bioengineering, Nanjing, China). Soluble sugar concentration was measured by the anthrone method using the plant soluble sugar content test kit from Nanjing Jiancheng Bioengineering. Approximately $0.07 \mathrm{~g}$ leaf per sample was homogenized in $1.8 \mathrm{~mL}$ distilled water. The mixture was boiled in water for $10 \mathrm{~min}$ and centrifuged at $4000 \mathrm{rpm}$ for $10 \mathrm{~min}$. Supernatants were diluted by distilled water and then used to detect sugar concentration according to standard procedures. Citrus leaves were assessed from five shoots per treatment.

\subsection{Gene Relative Expression Detection}

Total leaf RNA was isolated by TRIzol reagent (Invitrogen, Carlsbad, CA, USA) and $1 \mu \mathrm{g}$ of the RNA was used to synthesis cDNA using the FastQuant RT Kit with gDNase (Tiangen, Beijing, China). The transcript levels of four target genes were analyzed by fluorescent real-time quantitative PCR: Non-expressor of Pathogenesis-Related genes 1 (CtNPR1), a well-known SA receptor; Pathogenesis related protein 1 (CtPR1), a SA marker gene, which encodes the SA inducing PR protein; allene oxide synthase (CtAOS), a gene for JA biosynthesis; and cysteine proteinase inhibitor (CtPI), which works downstream of JA, and encodes the JA inducing proteinase inhibitor. PCR was performed in $20-\mu \mathrm{L}$ reaction volumes containing 10.4- $\mu \mathrm{L} 2 \times$ SYBR Premix (Tiangen, Beijing, China), 7.6- $\mu \mathrm{L}$ water, $1-\mu \mathrm{L}$ gene-specific primers and $1-\mu \mathrm{L}$ cDNA template. Reactions were carried out on the Mx 3500P detection system (Stratagene, La Jolla, CA, USA). For each biological replicate (4 per treatment), three technical repeats were performed. The transcript changes of the target genes were compared to the reference gene glyceraldehyde-3-phosphate dehydrogenase-1 (CtGAPC1). Primers were designed from gene sequences in NCBI or from published sequences [33,34] (Table 1).

Table 1. Primers used in present study.

\begin{tabular}{ccc}
\hline Gene Function & Gene & Primer Sequence $\mathbf{( 5}^{\prime} \mathbf{3}^{\prime} \mathbf{)}$ \\
\hline Reference gene & CtGAPC1 & F: ACTCCAGAGGGATGATGTGG \\
& & R: ATGGGATCTCCTCTGGGTTC \\
Salicylic acid & CtNPR1 & F: TGATAAGACCTTGCCACAACAC \\
signaling & & R: ACCGCAGGATTCAGATCTATGT \\
& CtPR1 & F: ACTGCAATCTTGTGCATTCG \\
& & R: TTCACCCACAGTTTCACAGC \\
Jasmonic acid & CtAOS & F: GTTTCAGCTCGCTCCGTTAC \\
signaling & & R: GAGGTTGTGACACGCTTCCT \\
& CtPI & F: AATCTTCTCATCGCTTTATC \\
& & R: TGCTTCGCACTTACAACT \\
\hline
\end{tabular}

\subsection{Statistical Analysis}

SPSS 20 software (SPSS Inc., Chicago, IL, USA) was used for statistical analysis. Aphids that died or shoots that defoliated during experiment were excluded from analysis. Data for survival rate and cumulative fecundity were analyzed with repeated measures ANOVA. One way ANOVA with Tukey's HSD test was utilized for comparisons among the three treatments (conspecific pre-infestation, heterospecific pre-infestation, and control) for each aphid species. Results were deemed significantly different at $p<0.05$. Proportion data associated with aphid survival rate were arcsine square root transformed to meet assumptions of normality and homogeneity of variance before analysis. The original data were used for presentation. 


\section{Results}

\subsection{Effects on Life-History Parameters}

The differences were observed between the aphid species. The survival rate of $A$. spiraecola was higher on plants pre-infested with aphids of either species (versus controls) (Figure $1 \mathrm{~A})\left(F_{2,33}=4.831\right.$, $p<0.001$ ), although the same trend was not observed with T. citricida (Figure $1 \mathrm{~B})\left(F_{2,34}=1.255, p=0.298\right)$. The adult weight of $A$. spiraecola was lower when reared on plants pre-infested with conspecifics $\left(F_{2,42}=45.891, p<0.001\right)$, although the opposite trend was observed when plants were previously infested with T. citricida (Figure 1C). No differences in adult weight were measured when T. citricida was added to pre-infested plants (Figure $1 D)\left(F_{2,42}=0.069, p=0.933\right)$. Compared with controls, the pre-reproductive period of $A$. spiraecola was lower on plants previously infested with $T$. citricida but not with conspecifics (Figure $1 \mathrm{E})\left(F_{2,33}=7.353, p=0.002\right)$. Toxoptera citricida did not show difference in pre-reproductive period by pre-infestation (Figure $1 \mathrm{~F})\left(F_{2,34}=0.038, p=0.963\right)$. Finally, A. spiraecola exhibited increased reproductive output over 14 days on plants pre-infested with T. citricida, but not with conspecifics (Figure $1 G)\left(F_{2,33}=37.338, p<0.001\right)$. No similar trend in reproductive output was measured when $T$. citricida was added to pre-infested plants (Figure $1 \mathrm{H})\left(F_{2,34}=1.223, p=0.307\right)$.

\subsection{Effects on Feeding Behavior via EPG Measurements}

Aphis spiraecola feeding on plants pre-infested by conspecifics required less time to reach sustained phloem sap ingestion compared with controls (Figure $2 \mathrm{~K})\left(F_{2,61}=5.921, p=0.010\right.$ ), although other feeding parameters as measured by EPG were unaffected (Figure 2) $(p>0.05)$. More differences were observed when plants were pre-infested with T. citricida (heterospecific pre-infestation). In this case, A. spiraecola exhibited reduced time of pathway phase activity (Figure $2 \mathrm{~B})\left(F_{2,61}=3.235, p=0.046\right)$, intracellular probe (Figure $2 \mathrm{C})\left(F_{2,61}=3.911, p=0.025\right)$, and reduced the duration before the first sieve element salivation (Figure $2 \mathrm{~J})\left(F_{2,61}=4.612, p=0.014\right)$ and before the first sustained phloem sap ingestion (Figure $2 \mathrm{~K}$ ). The duration of phloem sap ingestion by $A$. spiraecola was also increased on plants pre-infested with heterospecifics (Figure $2 \mathrm{E})\left(F_{2,61}=7.761, p=0.001\right)$. For T. citricida, feeding on plants pre-infested by either aphid species did not affect the twelve feeding activity parameters (Figure 3) $(p>0.05)$. Moreover, unlike A. spiraecolai, T. citricida had no xylem absorption activity.

\subsection{Amino Acid and Soluble Sugar Concentration}

Infesting sweet orange plants with $A$. spiraecola enhanced total amino acid concentration (Figure $4 \mathrm{~A}$ ) $\left(F_{2,12}=24.199, p<0.010\right)$ and amino acid to sugar ratio (Figure $\left.4 C\right)\left(F_{2,12}=8.306, p=0.005\right)$ but did not affect soluble sugar concentration in sweet orange (Figure $4 \mathrm{~B})\left(F_{2,12}=0.245, p=0.787\right)$. Similarly, no significant difference was observed when plants were infested with $T$. citricida compared with control $(p>0.05)$.

\subsection{SA and JA Marker Gene Expression in Sweet Orange}

Infesting sweet orange plants with $A$. spiraecola enhanced the expression of SA marker genes $\operatorname{CtNPR1}\left(F_{2,33}=24.423, p<0.001\right)$ and $\operatorname{CtPR} 1\left(F_{2,33}=12.622, p<0.001\right)$, the JA marker genes CtAOS $\left(F_{2,33}=18.752, p<0.001\right)$ and $C t P I\left(F_{2,33}=27.174, p<0.001\right)$ (Figure 5$)$ compared with $T$. citricida infestation or control. By contrast, T. citricida infestation depressed JA, but not SA marker gene expression, when compared with controls. 

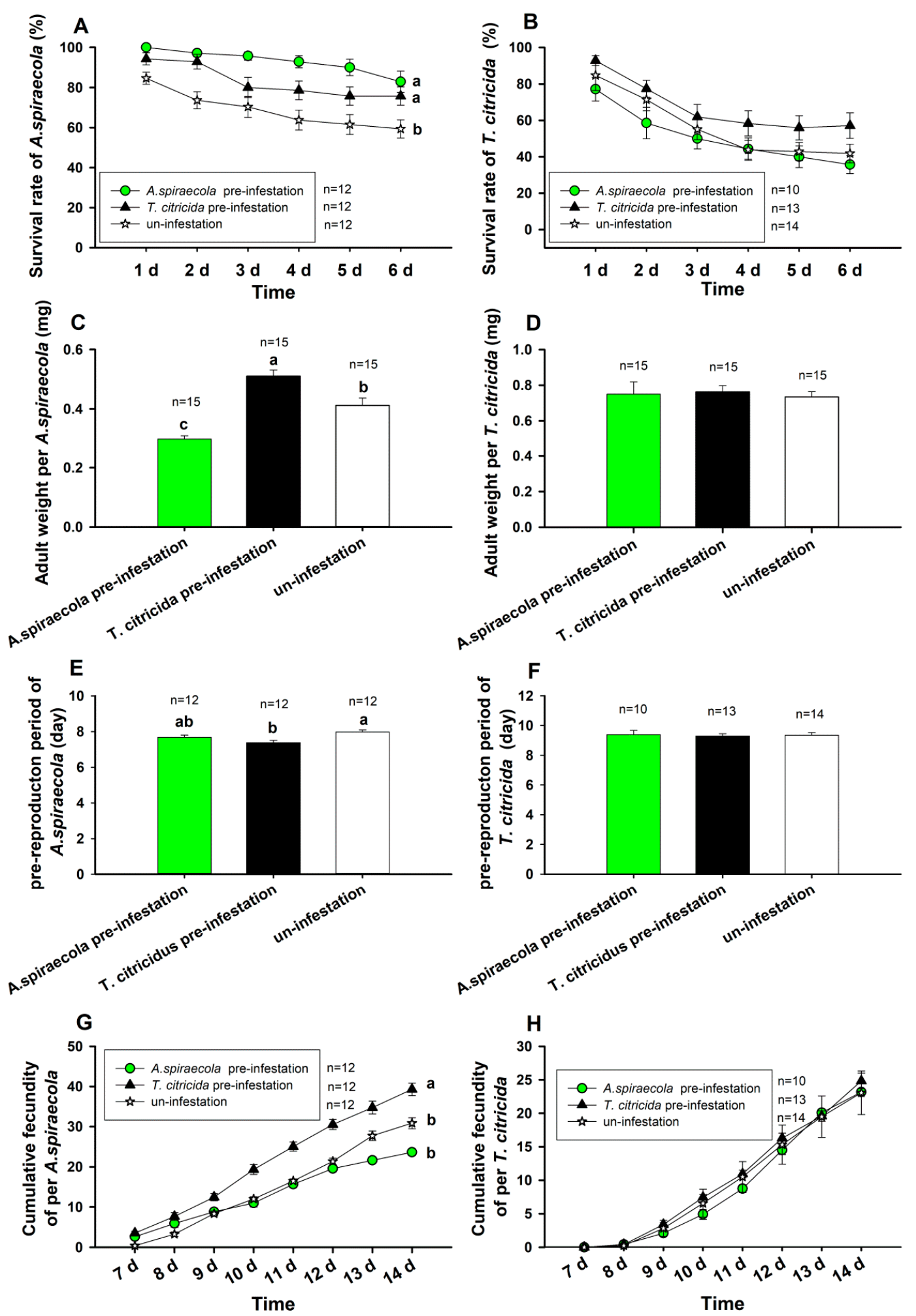

Figure 1. The life-history parameters of $A$. spiraecola and T. citricida feeding on sweet orange pre-infested by conspecific, heterospecific and without pre-infestation (control). The survival rate of $A$. spiraecola (A) and T. citricida (B), adult weight of $A$. spiraecola (C) and T. citricida (D), pre-reproductive period of $A$. spiraecola $(\mathbf{E})$ and T. citricida $(\mathbf{F})$, cumulative fecundity of $A$. spiraecola $(\mathbf{G})$ and T. citricida $(\mathbf{H})$ are represent the mean \pm SEM. The numbers of replication are noted after treatment legends or above the bars. Different letters represent significant difference (Tukey's HSD test, $p<0.05$ ). Bars or lines without letters indicate there is no significant difference between treatments. 

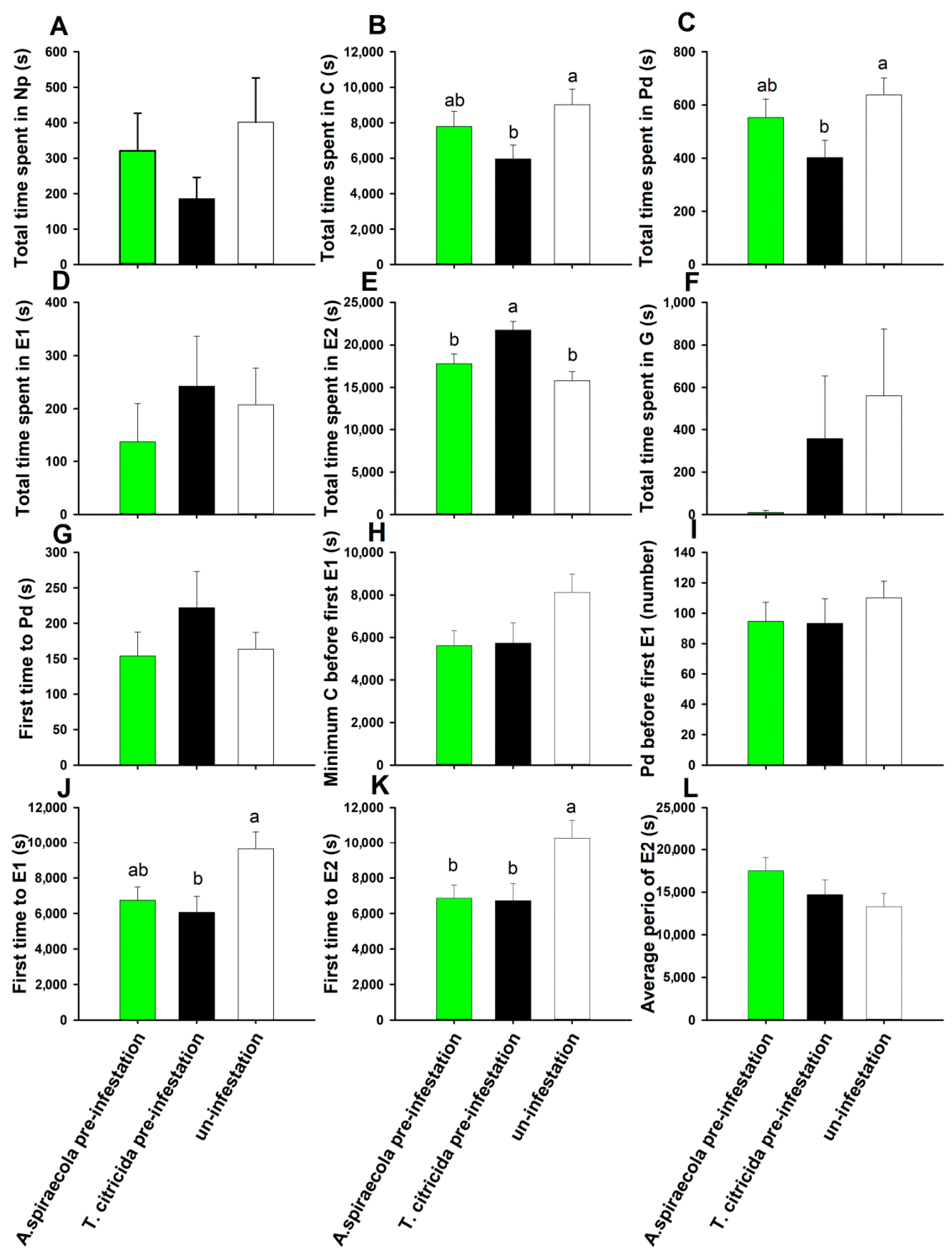

Figure 2. Effect of conspecfic and heterospecific pre-infestation on the feeding behavior of A. spiraecola. Values represent the mean $\pm \mathrm{SE}(\mathrm{n}=21-22)$. Bars with different letters represent significant difference (Tukey's HSD test, $p<0.05$ ) in each waveform event. Bars without letters indicate there is no significant difference between treatments. 
A
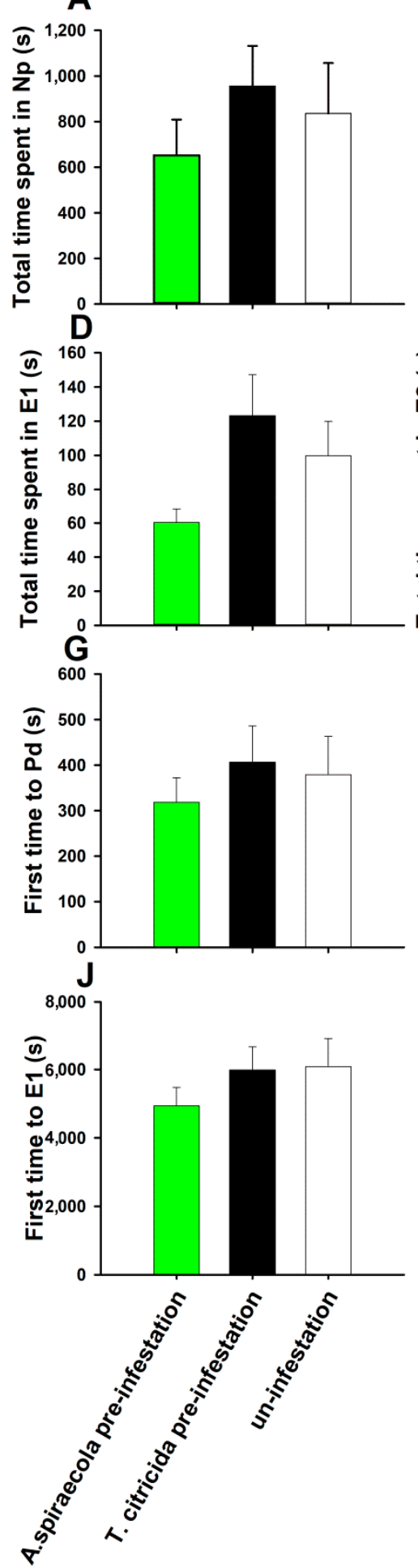

B
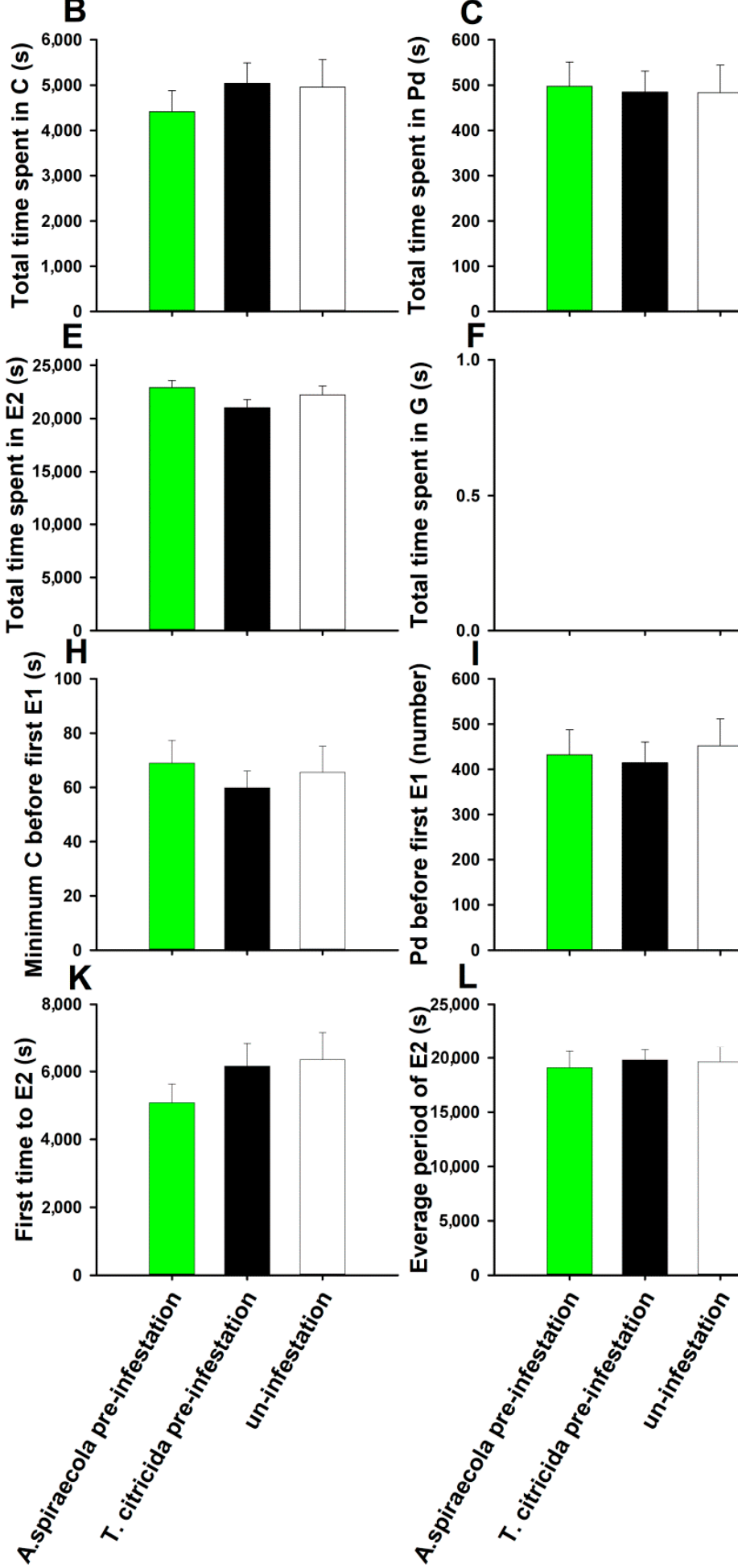

Figure 3. Effect of conspecfic and heterospecific pre-infestation on the feeding behavior of T. citricida. Values represent the mean $\pm \mathrm{SE}(\mathrm{n}=19-23)$. Bars with different letters represent significant difference (Tukey's HSD test, $p<0.05$ ) in each waveform event. Bars without letters indicate there is no significant difference between treatments. 

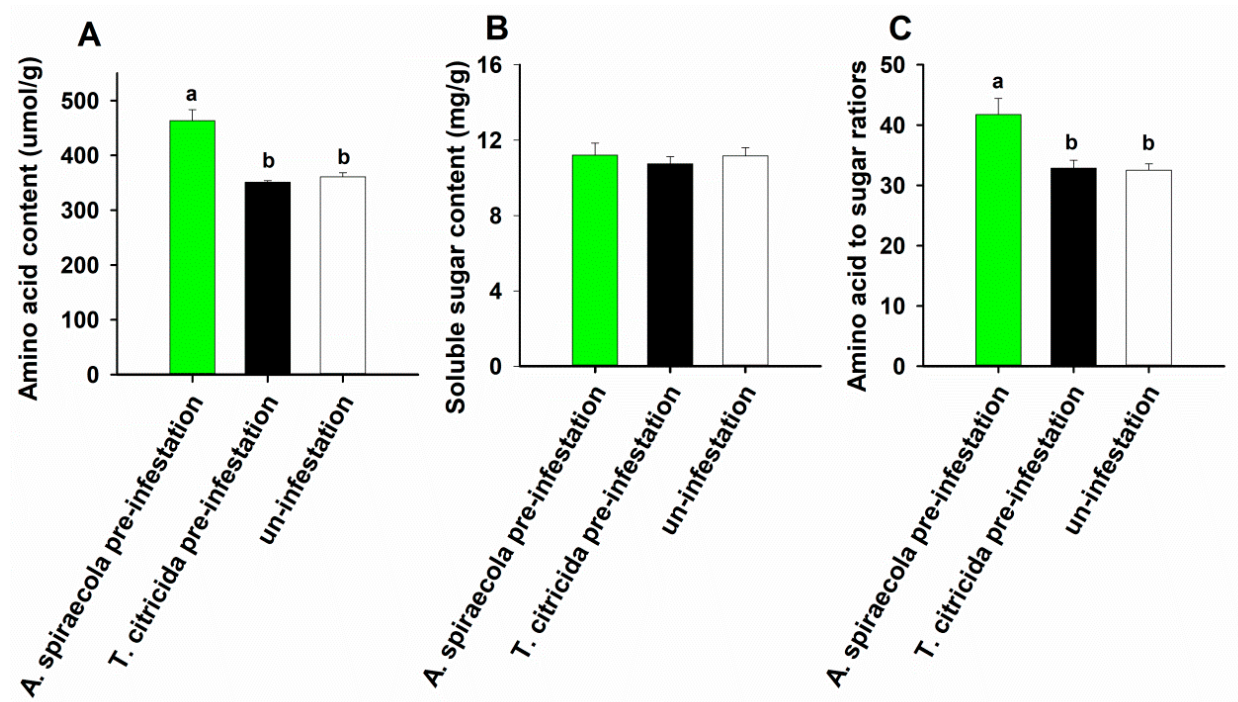

Figure 4. Amino acid concentration (A), soluble sugar concentration (B), and amino acid to sugar ratios (C) in sweet orange leaves pre-infested by A. spiraecola, T. citricida, or without aphid pre-infestation. Values represent the mean \pm SE (Tukey's HSD test, $\mathrm{n}=5$ ). Bars with different letters represent significant difference $(p<0.05)$. Bars without letters indicate there is no significant difference between treatments.
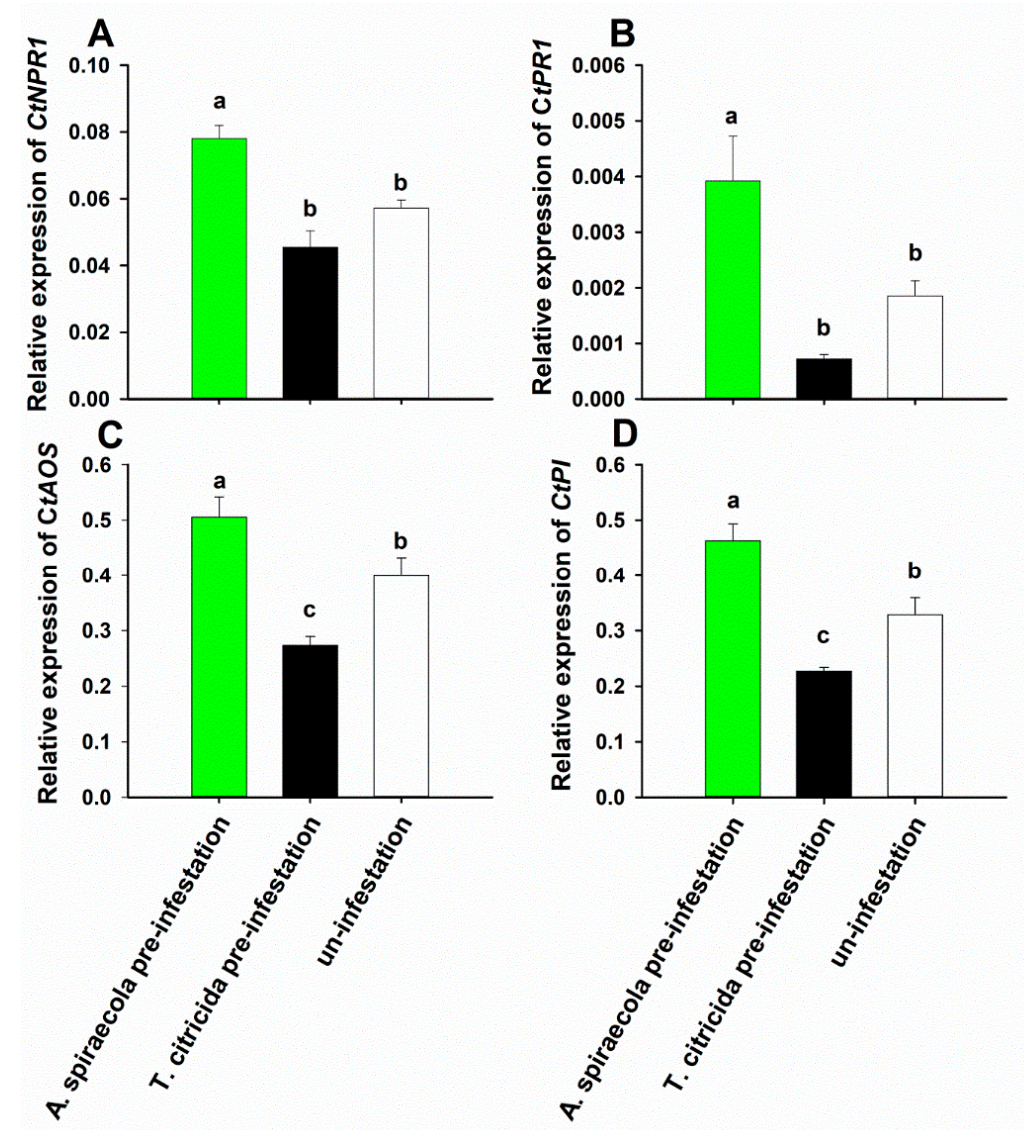

Figure 5. Relative expression of salicylic acid (A,B) and jasmonic acid (C,D) marker genes in $A$. spiraecola pre-infested, T. citricida pre-infested, or un-infested sweet orange. Gene expression levels were evaluated relative to $C t G A P C$. Values represent the mean $\pm S E(n=4)$. Bars with different letters represent significant difference (Tukey's HSD test, $p<0.05$ ). 


\section{Discussion}

Here, we found an asymmetrical interaction on the performance and feeding behavior of two citrus aphids. We observed that $A$. spiraecola gained enhanced survival rate from conspecific pre-infestation, and gained fitness benefits in survival rate, adult weight, and fecundity from heterospecific pre-infestation. However, T. citricida was not affected by either conspecific or heterospecific pre-infestation. Pre-infestation-induced interaction favors $A$. spiraecola as a superior competitor, and may influence the population and community of citrus aphid species.

The reciprocal effects of different herbivore species that share the same host plant have gained much attention. We found a positive effect on $A$. spiraecola and neutral effect on T. citricida induced by heterospecific pre-infestation. This is different to the most reported detrimental effect on other species, such as whitefly pre-infestation negatively affected performance of $M$. persicae [35], leaf miners [36,37], and Pieris rapae [38], which may help whitefly become a strong competitor. Here, A. spiraecola gains fitness benefit in the interspecific interaction through promoting performance of itself rather than inhibiting other species. In addition to the performance change, feeding behavior detected by EPG technique allows quantification of aphid response, and may help explain how aphid are affected by pre-infestation [39]. Aphis spiraecola on heterospecific pre-infested plant spent less time on penetration or pathway phase, spent more time on phloem sap ingestion, and gained quicker access and acceptance of phloem sieve elements. These feeding behavior parameters indicate heterospecific pre-infestation enhanced plant susceptibility to A. spiraecola [40,41], which was consistent with enhanced performance. On the other hand, in line with the performance, feeding behavior of T. citricida was also not affected by A. spiraecola pre-infestation. Toxoptera citricida pre-infestation showed a positive effect on $A$. spiraecola; thus, the management of $T$. citricida may reduce the fitness of $A$. spiraecola, indicating additional secondary benefits of controlling T. citricida.

Sap-sucking insects like aphids often aggregate in the feeding site, thus conspecific pre-infestation usually occurs to affect insect performance [42]. Con-specific pre-infestation enhanced the survival rate, decreased adult weight, and decreased the time spent before phloem sap ingestion for $A$. spiraecola compared with control. It has been shown that $A$. spiraecola feeding caused leaf curling, which would reduce the space provided for aphids. In addition, the enhanced survival rate caused by conspecific pre-infestation increased the number of aphids. These factors would enhance the density of $A$. spiraecola, a factor important in producing the winged form of aphids $[43,44]$. The winged form would help it disperse to more new shoots or plants. Therefore, conspecific pre-infestation is thought to favor $A$. spiraecola fitness. In contrast, T. citricida pre-infestation did not affect performance or feeding behavior of con-specifics. When considering both the intra- and inter-specific effects, for A spiraecola, the conspecific pre-infestation effect is less strong than that of heterospecific (only the enhanced survival rate vs enhanced performance of all the tested life history parameters), while for T. citricida, the conspecific and heterospecific effect did not differ (both are unchanged). Thus, the pre-infestation may intensify intermore than intra-specific competition between citrus aphids. Besides, the conspecific and heterospecific pre-infestation induced a positive synergistic effect on $A$. spiraecola, which may help explain why it has become a dominant species in the citrus groves in America [23].

Herbivore-induced changes in host plant morphology, nutrition, defense, or some combination of these changes mediated an alteration of the performance of subsequent infested insects [45-47]. In our study, T. citricida pre-infestation did not affect SA signaling marker genes expression, but depressed those involved in JA signaling. As the JA-dependent defense is considered effective in conferring resistance against phloem-sucking insects [48], the depressed defense may benefit subsequently infested aphids. Concurrently, we observed that $A$. spiraecola feeding on heterospecific infested plants had better performance and enhanced feeding efficiency. Particularly, the less time before reaching phloem sap and passive phloem ingestion also indicate the decreased mesophyll/phloem resistance it encountered [30]. Interestingly, plants pre-infested with $A$. spiraecola showed increased SA and JA signaling gene expression, but did not affect the performance of subsequent infested T. citricida, indicating that other factors such as nutrition change may involve. Amino acid concentration and amino 
acid to sugar ratio are considered as an index of host plant nutrient quality for aphids [18]. Positive correlations between growth, reproduction and plant amino acid concentration were established in Rhopalosiphum insertum and M. persicae [9,49]. The infestation of $A$. spiraecola enhanced the amino acid concentration and amino acid to sugar ratio. We hypothesis that the beneficial effect of enhanced nutrition counteract the detrimental effect of induced defense, which results in unchanged performance of $T$. citricida by heterospecific pre-infestation. For the conspecific interaction, even feeding on plant with enhanced phytohormone-dependent defense, $A$. spiraecola feeding behavior reflects the fact that it encountered a decreased mesophyll/phloem resistance. It is possible that $A$. spiraecola can overcome the induced defense, and the decreased adult weight reflects energy cost of detoxification [50]. Therefore, both pre-infestation-induced changes in defenses and nutrition were involved in the indirect interaction between citrus aphids. However, although T. citricida repressed JA defense, the performance and feeding behavior of subsequent infested conspecific is not affected, may be T. citricida is less likely to be affected by plant defense through the long-term co-evolution with host plant. The quality of the plant after insect feeding on a pre-infested plant will help fully explain pre-infestation effect on conspecifics and heterospecifics.

\section{Conclusions}

To our knowledge, this is the first study to investigate plant-mediated effects on performance and feeding behavior of different citrus aphids. A. spiraecola and T. citricida show asymmetric interaction induced by pre-infestation. Particularly, T. citricida pre-infestation caused A. spiraecola to gain more fitness. Furthermore, pre-infestation-induced changes in phytohormone-dependent defense and nutritional quality probably underlie the asymmetric interaction. Moreover, the two citrus aphids manipulate host plant physiology in distinct ways, which may relate to the different adaptive strategy between oligophagous and polyphagous insects through the long term co-evolution with host plant [51].

Author Contributions: J.G. and R.M. planned and designed the research. J.G. conducted experiments and analyzed data. J.G., S.A., and R.M. wrote the manuscript. All authors have read and agreed to the published version of the manuscript.

Funding: This research was funded by the GDAS Special Project of Science and Technology Development (2019GDASYL-0103055, 2018GDASCX-0107), Science and Technology Planning Project of Guangdong Province (No. 2017B020202005).

Conflicts of Interest: The authors declare no conflict of interest.

\section{References}

1. Zhang, X.; Xue, M.; Zhao, H.P. Species-specific effects on salicylic acid content and subsequent Myzus persicae (Sulzer) performance by three phloem-sucking insects infesting Nicotiana tabacum L. Anthr. Plant Interact. 2015, 9, 383-391. [CrossRef]

2. Tan, X.L.; Wang, S.; Ridsdill-Smith, J.; Liu, T.X. Direct and Indirect Impacts of Infestation of Tomato Plant by Myzus persicae (Hemiptera: Aphididae) on Bemisia tabaci (Hemiptera: Aleyrodidae). PLoS ONE 2014, 9, e94310. [CrossRef]

3. Ohgushi, T. Indirect interaction webs: Herbivore-induced effects through trait change in plants. Annu. Rev. Ecol. Evol. Syst. 2005, 36, 81-105. [CrossRef]

4. Saad, K.A.; Roff, M.M.; Hallett, R.H.; Idris, A. Aphid-induced defences in chilli affect preferences of the whitefly, Bemisia tabaci (Hemiptera: Aleyrodidae). Sci Rep. 2015, 5, 1-9. [CrossRef] [PubMed]

5. Zhao, H.P.; Zhang, X.Y.; Xue, M.; Zhang, X. Feeding of whitefly on tobacco decreases aphid performance via increased salicylate signaling. PLoS ONE 2015, 10, e0138584. [CrossRef] [PubMed]

6. Matsumura, M.; Suzuki, Y. Direct and feeding-induced interactions between two rice planthoppers, Sogatella furcifera and Nilaparvata lugens: Effects on dispersal capability and performance. Ecol. Entomol. 2003, 28, 174-182. [CrossRef] 
7. Nombela, G.; Garzo, E.; Duque, M.; Muñiz, M. Preinfestations of tomato plants by whiteflies (Bemisia tabaci) or aphids (Macrosiphum euphorbiae) induce variable resistance or susceptibility responses. Bull. Entomol. Res. 2009, 99, 183-191. [CrossRef]

8. Davidson, L.E.; Szendrei, Z.; Ali, J.G. Asymmetric effects of a leaf-chewing herbivore on aphid population growth. Ecol. Entomol. 2019, 44, 81-92. [CrossRef]

9. Cao, H.H.; Liu, H.R.; Zhang, Z.F.; Liu, T.X. The green peach aphid Myzus persicae perform better on pre-infested Chinese cabbage Brassica pekinensis by enhancing host plant nutritional quality. Sci Rep. 2016, 6, 21954. [CrossRef]

10. McNutt, D.W.; Underwood, N. Variation in plant-mediated intra- and interspecific interactions among insect herbivores: Effects of host genotype. Ecosphere 2016, 7, e01520. [CrossRef]

11. Inbar, M.; Eshel, A.; Wool, D. Interspecific competition among phloem-feeding insects mediated by induced host-plant sinks. Ecology 1995, 76, 1506-1515. [CrossRef]

12. Triyogo, A.; Yasuda, H. Effect of host-plant manipulation by a gall-inducing insect on abundance of herbivores on chestnut trees. Appl. Entomol. Zoolog. 2013, 48, 345-353. [CrossRef]

13. Erb, M. Plant Defenses against Herbivory: Closing the Fitness Gap. Trends Plant Sci. 2018, 23, $187-194$. [CrossRef]

14. Thaler, J.S.; Humphrey, P.T.; Whiteman, N.K. Evolution of jasmonate and salicylate signal crosstalk. Trends Plant Sci. 2012, 17, 260-270. [CrossRef]

15. Stewart, S.A.; Hodge, S.; Bennett, M.; Mansfield, J.W.; Powell, G. Aphid induction of phytohormones in Medicago truncatula is dependent upon time post-infestation, aphid density and the genotypes of both plant and insect. Anthr. Plant Interact. 2016, 10, 41-53. [CrossRef]

16. Cui, H.Y.; Sun, Y.C.; Su, J.W.; Li, C.Y.; Ge, F. Reduction in the Fitness of Bemisia tabaci Fed on Three Previously Infested Tomato Genotypes Differing in the Jasmonic Acid Pathway. Environ. Entomol. 2012, 41, 1443-1453. [CrossRef] [PubMed]

17. Takemoto, H.; Uefune, M.; Ozawa, R.; Arimura, G.-I.; Takabayashi, J. Previous infestation of pea aphids Acyrthosiphon pisum on broad bean plants resulted in the increased performance of conspecific nymphs on the plants. J. Plant Interact. 2013, 8, 370-374. [CrossRef]

18. Awmack, C.S.; Leather, S.R. Host plant quality and fecundity in herbivorous insects. Annu. Rev. Entomol. 2002, 47, 817-844. [CrossRef]

19. Gao, J.; Guo, H.J.; Sun, Y.C.; Ge, F. Differential accumulation of leucine and methionine in red and green pea aphids leads to different fecundity in response to nitrogen fertilization. Pest. Manag. Sci. 2018, 74, 1779-1789. [CrossRef]

20. Talon, M.; Gmitter, F.G. Citrus genomics. Int. J. Plant. Gen. 2008, 2008, 528361. [CrossRef]

21. Brlansky, R.H.; Damsteegt, V.D.; Howd, D.S.; Roy, A. Molecular analyses of Citrus tristeza virus subisolates separated by aphid transmission. Plant Dis. 2003, 87, 397-401. [CrossRef] [PubMed]

22. Hall, D.G.; Albrigo, L.G. Estimating the relative abundance of flush shoots in citrus with implications on monitoring insects associated with flush. HortScience 2007, 42, 364-368. [CrossRef]

23. Powell, C.A.; Burton, M.S.; Pelosi, R.R.; Rundell, P.A.; Ritenour, M.A.; Bullock, R.C. Six-year evaluation of brown citrus and spirea aphid populations in a citrus grove and the effects of insecticides on these populations. HortScience 2006, 41, 688-690. [CrossRef]

24. Brlansky, R.H.; Roy, A.; Damsteegt, V.D. Stem-pitting Citrus tristeza virus predominantly transmitted by the brown citrus aphid from mixed infections containing non-stem-pitting and stem-pitting isolates. Plant Dis. 2011, 95, 913-920. [CrossRef] [PubMed]

25. Mostefaoui, H.; Allal-Benfekih, L.; Djazouli, Z.E.; Petit, D.; Saladin, G. Why the aphid Aphis spiraecola is more abundant on clementine tree than Aphis gossypii? C. R. Biol. 2014, 337, 123-133. [CrossRef]

26. Elhaddad, A.; ElAmrani, A.; Fereres, A.; Moreno, A. Spatial and temporal spread of Citrus tristeza virus and its aphid vectors in the North western area of Morocco. Insect Sci. 2016, 23, 903-912. [CrossRef]

27. Zhang, Y.H.; Wang, Y.L.; Wang, Q.J.; Cao, M.; Zhou, C.Y.; Zhou, Y. Identification of Aphis spiraecola as a vector of Citrus yellow vein clearing virus. Eur. J. Plant Pathol. 2018, 152, 841-844. [CrossRef]

28. Hu, X.; Liu, X.; Zhao, H. Development and application of electrical penetration graph (EPG) technique. Plant. Prot. 2006, 32, 1-4.

29. Gao, J.; Guo, H.J.; Sun, Y.C.; Ge, F. Juvenile hormone mediates the positive effects of nitrogen fertilization on weight and reproduction in pea aphid. Pest. Manag. Sci. 2018, 74, 2511-2519. [CrossRef] 
30. Alvarez, A.E.; Tjallingii, W.F.; Garzo, E.; Vleeshouwers, V.; Dicke, M.; Vosman, B. Location of resistance factors in the leaves of potato and wild tuber-bearing Solanum species to the aphid Myzus persicae. Entomol. Exp. Appl. 2006, 121, 145-157. [CrossRef]

31. Eleftherianos, I.; Vamvatsikos, P.; Ward, D.; Gravanis, F. Changes in the levels of plant total phenols and free amino acids induced by two cereal aphids and effects on aphid fecundity. J. Appl. Entomol. 2006, 130, 15-19. [CrossRef]

32. Weibull, J.; Brishammar, S.; Pettersson, J. Amino acid analysis of phloem sap from oats and barley: A combination of aphid stylet excision and high performance liquid chromatography. Entomol. Exp. Appl. 1986, 42, 27-30. [CrossRef]

33. Nehela, Y.; Hijaz, F.; Elzaawely, A.A.; El-Zahaby, H.M.; Killiny, N. Citrus phytohormonal response to Candidatus Liberibacter asiaticus and its vector Diaphorina citri. Physiol. Mol. Plant Pathol. 2018, 102, 24-35. [CrossRef]

34. Ibanez, F.; Suh, J.H.; Wang, Y.; Stelinski, L.L. Long-term, sustained feeding by Asian citrus psyllid disrupts salicylic acid homeostasis in sweet orange. BMC Plant Biol. 2019, 19, 493. [CrossRef] [PubMed]

35. Xue, M.; Wang, C.X.; Bi, M.J.; Li, Q.L.; Liu, T.X. Induced Defense by Bemisia tabaci Biotype B (Hemiptera: Aleyrodidae) in Tobacco Against Myzus persicae (Hemiptera: Aphididae). Environ. Entomol. 2010, 39, 883-891. [CrossRef] [PubMed]

36. Inbar, M.; Doostdar, H.; Leibee, G.L.; Mayer, R.T. The role of plant rapidly induced responses in asymmetric interspecific interactions among insect herbivores. J. Chem. Ecol. 1999, 25, 1961-1979. [CrossRef]

37. Zhang, L.P.; Zhang, G.Y.; Zhang, Y.J.; Zhang, W.J.; Liu, Z. Interspecific interactions between Bemisia tabaci (Hem., Aleyrodidae) and Liriomyza sativae (Dipt., Agromyzidae). J. Appl. Entomol. 2005, 129, 443-446. [CrossRef]

38. Zhang, S.Z.; Huang, H.; Shan, H.W.; Zhang, F.; Wan, F.H.; Liu, T.X. Defense against Pieris rapae in cabbage plants induced by Bemisia tabaci biotype B. Entomol. Exp. Appl. 2013, 147, 293-300. [CrossRef]

39. Ramírez, C.C.; Niemeyer, H.M. The influence of previous experience and starvation on aphid feeding behavior. J. Insect Behav. 2000, 13, 699-709. [CrossRef]

40. Dardeau, F.; Pointeau, S.; Ameline, A.; Laurans, F.; Cherqui, A.; Lieutier, F.; Sallé, A. Host manipulation by a herbivore optimizes its feeding behaviour. Anim. Behav. 2014, 95, 49-56. [CrossRef]

41. Brunissen, L.; Cherqui, A.; Pelletier, Y.; Vincent, C.; Giordanengo, P. Host-plant mediated interactions between two aphid species. Entomol. Exp. Appl. 2009, 132, 30-38. [CrossRef]

42. Gonzales, W.L.; Ramirez, C.C.; Olea, N.; Niemeyer, H.M. Host plant changes produced by the aphid Sipha flava: Consequences for aphid feeding behaviour and growth. Entomol. Exp. Appl. 2002, 103, 107-113. [CrossRef]

43. Braendle, C.; Davis, G.K.; Brisson, J.A.; Stern, D.L. Wing dimorphism in aphids. Heredity 2006, 97, 192-199. [CrossRef] [PubMed]

44. Purandare, S.R.; Tenhumberg, B.; Brisson, J.A. Comparison of the wing polyphenic response of pea aphids (Acyrthosiphon pisum) to crowding and predator cues. Ecol. Entomol. 2014, 39, 263-266. [CrossRef] [PubMed]

45. Hoysted, G.A.; Lilley, C.J.; Field, K.J.; Dickinson, M.; Hartley, S.E.; Urwin, P.E. A Plant-Feeding Nematode Indirectly Increases the Fitness of an Aphid. Front. Plant Sci. 2017, 8, 1897. [CrossRef]

46. Van Dam, N.M.; Wondafrash, V.; Mathur, V.; Tytgat, T.O.G. Differences in Hormonal Signaling Triggered by Two Root-Feeding Nematode Species Result in Contrasting Effects on Aphid Population Growth. Front. Ecol. Evol. 2018, 6, 88. [CrossRef]

47. Denno, R.F.; Peterson, M.A.; Gratton, C.; Cheng, J.A.; Langellotto, G.A.; Huberty, A.F.; Finke, D.L. Feeding-induced changes in plant quality mediate interspecific competition between sap-feeding herbivores. Ecology 2000, 81, 1814-1827. [CrossRef]

48. Zarate, S.I.; Kempema, L.A.; Walling, L.L. Silverleaf whitefly induces salicylic acid Defenses and suppresses effectual jasmonic acid defenses. Plant Physiol. 2007, 143, 866-875. [CrossRef]

49. Koyama, Y.; Yao, I.; Akimoto, S.I. Aphid galls accumulate high concentrations of amino acids: A support for the nutrition hypothesis for gall formation. Entomol. Exp. Appl. 2004, 113, 35-44. [CrossRef] 
50. Castañeda, L.E.; Figueroa, C.C.; Fuentes-Contreras, E.; Niemeyer, H.M.; Nespolo, R.F. Energetic costs of detoxification systems in herbivores feeding on chemically defended host plants: A correlational study in the grain aphid. Sitobion avenae J. Exp. Biol. 2009, 212, 1185-1190. [CrossRef]

51. Ali, J.G.; Agrawal, A.A. Specialist versus generalist insect herbivores and plant defense. Trends Plant Sci. 2012, 17, 293-302. [CrossRef] [PubMed]

(C) 2020 by the authors. Licensee MDPI, Basel, Switzerland. This article is an open access article distributed under the terms and conditions of the Creative Commons Attribution (CC BY) license (http://creativecommons.org/licenses/by/4.0/). 